\title{
Níveis de lisina, com base no conceito de proteína ideal, em rações para alevinos de tilápia-do-nilo ${ }^{1}$
}

\section{Marcos Antonio Delmondes Bomfim ${ }^{2 *}$, Eduardo Arruda Teixeira Lanna ${ }^{3}$, Juarez Lopes Donzele $^{3}$, Moisés Quadros ${ }^{2}$, Felipe Barbosa Ribeiro², Maíra Paula de Sousa ${ }^{4}$}

\author{
1 Projeto financiado pela FAPEMIG. \\ 2 Pós-graduação em Zootecnia-DZO/UFV. \\ ${ }^{3}$ Departamento de Zootecnia-DZO/UFV. \\ 4 Petrobrás.
}

RESUMO - Avaliaram-se os efeitos dos níveis de lisina digestível da ração, com base no conceito de proteína ideal, no desempenho de alevinos de de tilápia-do-nilo (Oreochromis niloticus). Utilizaram-se 432 alevinos revertidos, linhagem tailandesa, com peso inicial de 1,12 $\pm 0,02 \mathrm{~g}$, em delineamento inteiramente ao acaso, composto de 6 dietas, 6 repetições e 12 peixes por unidade experimental. Como tratamentos, avaliaram-se uma dieta basal com 29,12\% de proteína bruta e 3.000 kcal de energia digestível/kg, suplementada com aminoácidos sintéticos, resultando em dietas com 0,95; 1,10; 1,25; 1,40; 1,55 e $1,70 \%$ de lisina digestível e relações mínimas entre metionina + cistina, treonina, triptofano, isoleucina e arginina com a lisina (66, 77, 23, 64 e 85\%, respectivamente), com base em valores digestíveis. Os peixes foram mantidos em aquários de 130 litros, dotados de abastecimento de água, temperatura controlada e aeração individual, e alimentados à vontade em seis refeições diárias durante 30 dias. Avaliaram-se os parâmetros de desempenho, a composição corporal, a deposição de proteína e gordura corporais e a eficiência de retenção de nitrogênio dos peixes. A elevação do teor de lisina digestível na ração não influenciou a taxa de sobrevivência e o teor de gordura corporal dos peixes, mas melhorou de forma linear todos os demais parâmetros avaliados, com exceção da eficiência de utilização de lisina e a umidade corporal, que pioraram de forma quadrática e linear, respectivamente. O nível de 1,80\% de lisina total (0,600\% Mcal de ED) e o de 1,70\% de lisina digestível (0,567\% Mcal de ED) proporcionam os melhores resultados de desempenho e características de carcaça de alevinos de tilápia-do-nilo quando se utiliza o conceito de proteína ideal na formulação das rações experimentais.

Palavras-chave: aminoácidos digestíveis, aminoácidos sintéticos, exigência de lisina digestível, fase inicial, nutrição proteica, Oreochromis niloticus

\section{Lysine levels, based on the ideal protein concept, in diets for Nile tilapia fingerlings}

ABSTRACT - The effects of the digestible lysine level were assessed in feeds for Nile tilapia fingerlings (Oreochromis niloticus), based on the ideal protein concept. Four hundred and thirty two reverted fingerlings were used, average weight 1.12 $\pm 0.02 \mathrm{~g}$, in a randomized complete design, consisting of 6 feeds, six replications and twelve fish per experimental unit. The diets consisted of a basal diet with $29.12 \%$ crude protein and 3,000 kcal/kg digestible energy, supplemented with synthetic amino acids, resulting in six diets with $0.95 ; 1.10 ; 1.25 ; 1.40 ; 1.55$ and $1.70 \%$ digestible lysine and minimum ratios between methionine plus cystine, threonine, thryptophan, isoleucine, arginine with the lysine (66, 77, 23, 64 and 85\%, respectively), based on digestible values. The fish were maintained in 130 liter aquaria equipped with individual water and controlled temperature and aeration. The fish were fed to apparent satiation, six times a day, for 30 days. Growth performance, body composition, body protein and fat deposition and nitrogen retention efficiency of the fish were evaluated. The increase in the dietary digestible lysine did not affect the survival rate and body fat level of the fishes. However, there was linear improvement in all the other parameters assessed, except lysine use efficiency and the body humidity, that showed quadratic and lineardecline, respectively. The levels of 1.80 (0.600\% Mcal of DE) total lysine and 1.70\% (0.567\% Mcal of DE) digestible lysine, respectively, result in the best performance and carcass characteristics of Nile tilapia fingerlings, when the ideal protein concept is used to formulate the experimental diets.

Key Words: digestible amino acids, digestible lysine requirements, initial phase, Oreochromis niloticus, proteic nutrition, synthetic amino acids

Recebido em 6/11/2007 e aprovado em 12/2/2009. 


\section{Introdução}

A determinação da exigência dietética de lisina tem sido priorizada na nutrição de peixes. A lisina é um aminoácido indispensável encontrado em maior concentração na carcaça desses animais, além de ser o primeiro aminoácido limitante em algumas fontes proteicas alternativas à farinha de peixe, principalmente nos cereais, como o glúten, e também por ser o aminoácido de referência na aplicação do conceito de proteína ideal (Boisen et al., 2000; Hauler \& Carter, 2001; Furuya et al., 2004; Rollin et al., 2003; Furuya et al., 2006).

As informações sobre as exigências de lisina em rações para tilápia-do-nilo, além da grande variabilidade, têm sido expressas em valores totais (Jackson \& Capper, 1982; Santiago \& Lovell, 1988; Furuya et al., 2004), com exceção do estudo conduzido por Furuya et al. (2006), ou utilizam elevada quantidade de aminoácidos sintéticos nas rações experimentais, que, em ambos os casos, podem gerar valores de exigência imprecisos (Cowey, 1994; Wilson, 2003; Lanna et al., 2005; Bomfim et al., 2005).

A utilização de linhagens de baixo desempenho (Jackson \& Capper, 1982; Santiago \& Lovell, 1988; Boscolo et al., 2002a) e a fixação dos níveis dos demais aminoácidos nas rações (diferentes relações aminoácido: lisina) (Jackson \& Capper, 1982; Santiago \& Lovell, 1988; Furuya et al., 2004; Furuya et al., 2006) também podem limitar a resposta dos animais, subestimando as exigências de lisina (Fontes et al., 2000; Conhalato et al., 2002; Valério et al., 2003; Bomfim et al., 2005; Abreu et al., 2006).

Com base nesse pressuposto, têm-se utilizado o conceito de proteína ideal na formulação de rações experimentais, pelo qual a mudança nas concentrações dos níveis de lisina digestível nas rações são acompanhadas de alterações proporcionais dos demais aminoácidos, ou, pelo menos, são mantidas relações mínimas destes aminoácidos com a lisina, para que não limitem a possibilidade de utilização de cada nível de lisina testado para o desempenho dos animais (Fontes et al., 2000; Conhalato et al., 2002; Valério et al., 2003; Boisen, 2003; Abreu et al., 2006).

Assim, realizou-se este trabalho com o objetivo de avaliar os efeitos dos níveis de lisina digestível, com base no conceito de proteína ideal, em rações para alevinos da tilápia-do-nilo (Oreochromis niloticus).

\section{Material e Métodos}

O experimento foi conduzido entre os meses de agosto e setembro de 2005 e teve duração de 30 dias. Utilizaram-se 432 alevinos revertidos de tilápia (Oreochromis niloticus), da linhagem tailandesa, com peso inicial de 1,12 $\pm 0,02 \mathrm{~g}$, em um delineamento inteiramente casualizado, composto de 6 tratamentos, 6 repetições por tratamento e 12 peixes por unidade experimental.

Avaliou-se o efeito de uma dieta basal suplementada com cinco níveis de L-lisina-HCl 78,4\%, constituindo diferentes níveis de lisina digestível $(0,95 ; 1,10 ; 1,25 ; 1,40$; $1,55$; e $1,70 \%)$, mantendo-se a relação dos demais aminoácidos:lisina pelo menos três pontos percentuais acima daquelas estimadas a partir dos valores de exigência recomendados pelo NRC (1993). Para que as dietas experimentais mantivessem o mesmo teor de prot ína bruta (isonitrogenadas) fossem isoenergéticas, a suplementação com os aminoácidos sintéticos para obtenção das relações mínimas aminoácido:lisina foi feita utilizando-se ácido glutâmico, amido e óleo (Tabela 1).

Os alevinos foram mantidos em 36 aquários de polietileno, com capacidade volumétrica de 150 litros e volume útil de 130 litros, dotados de sistemas individuais de aeração, abastecimento de água e escoamento de fundo disposto em sistema de recirculação e renovação mínima de água de $25,0 \%$ por dia.

A água de abastecimento dos aquários foi proveniente do sistema de tratamento de água da Universidade Federal de Viçosa - UFV, previamente declorada e aquecida por resistências elétricas, com temperatura controlada por termostato.

A temperatura da água foi mantida em torno de $28^{\circ} \mathrm{C}$ e aferida diariamente, às $7 \mathrm{~h} 30$ e $17 \mathrm{~h} 30$, com o auxílio de um termômetro de bulbo de mercúrio graduado de 0 a $50^{\circ} \mathrm{C}$. Os controles do $\mathrm{pH}$ e do teor de oxigênio dissolvido na água foram realizados a cada sete dias, respectivamente, utilizando-se potenciômetro e oxímetro.

O fotoperíodo foi mantido em 12 horas de luz, por meio de iluminação proveniente de lâmpadas mistas, controlado por timer automático.

As rações experimentais foram peletizadas e fornecidas diariamente, em seis refeições às 8 h, 10 h, 12 h, 14 h, 16 h e 18 h). Em cada refeição, as rações foram fornecidas em pequenas quantidades até a aparente saciedade, reduzindo a possibilidade de lixiviações.

A limpeza dos aquários foi realizada duas vezes por dia, para retirada das fezes por sifonagem, após as leituras da temperatura da água.

Foram avaliados os seguintes índices zootécnicos: ganho de peso, taxa de crescimento específico, taxa de sobrevivência, consumo de ração, consumo de lisina digestível, conversão alimentar, eficiência proteica para ganho, eficiência de lisina para ganho, taxas de deposição diária de proteína e gordura corporais, composição química 
Tabela 1 - Composição das dietas experimentais (\% matéria natural)

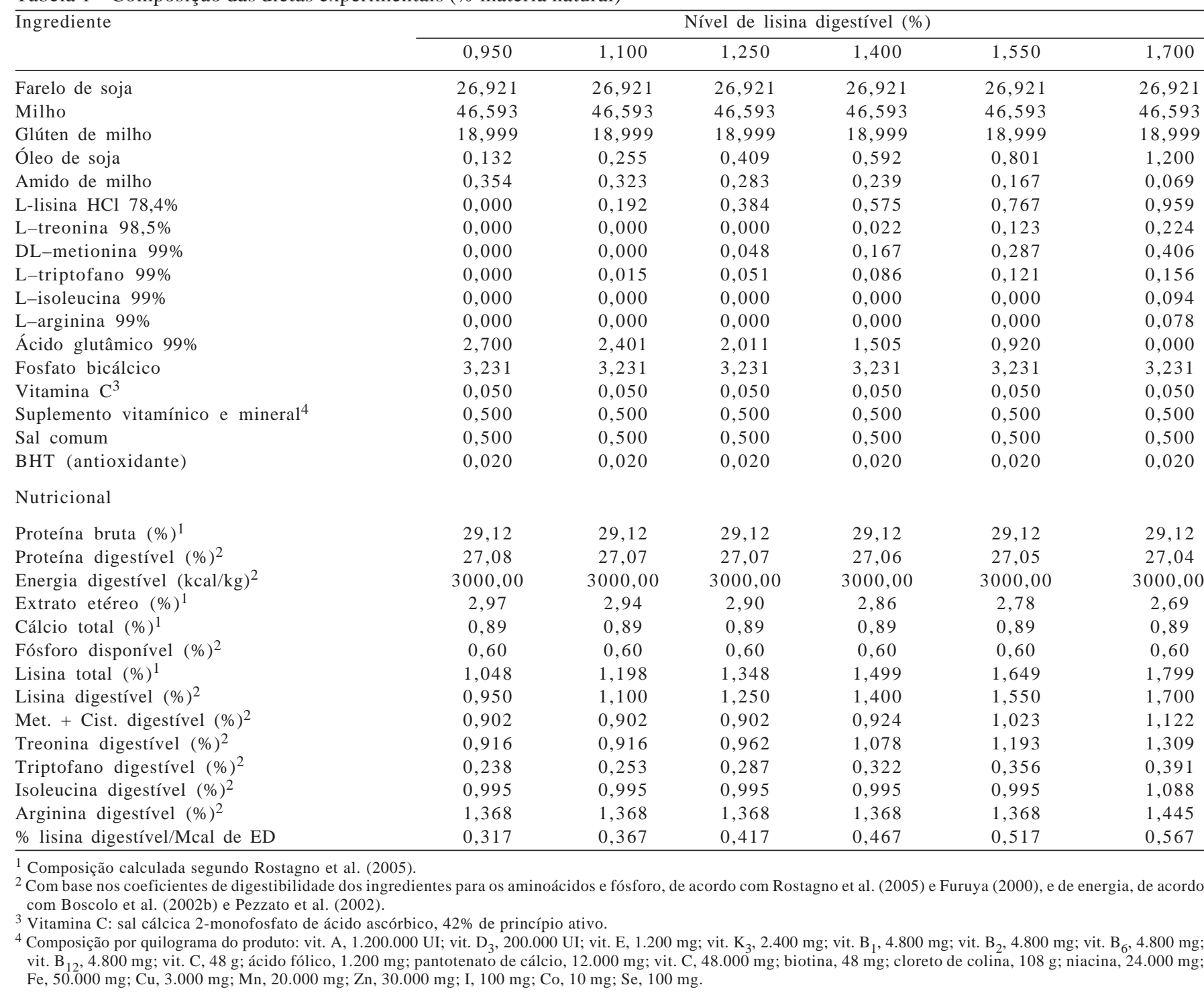

corporal (teores de umidade, proteína e gordura corporais) e eficiência de retenção de nitrogênio.

Para determinação da taxa de crescimento específico (TCE), foi empregada a equação abaixo, utilizando-se transformações logarítmicas.

$$
\begin{array}{r}
\mathrm{TCE}=\frac{\log \text { natural do peso final }(\mathrm{g})-\log \text { natural do }}{\text { peso inicial }(\mathrm{g}) \times 100} \\
\text { Período experimental (dias) }
\end{array}
$$

As eficiências de utilização de proteína e lisina para ganho foram calculadas dividindo-se o ganho de peso dos peixes pelo consumo de proteína bruta ou de lisina digestível, respectivamente.

Após insensibilização em água contendo gelo, 80 peixes foram sacrificados no início do experimento e oito, de forma idêntica e com pesos mais próximos ao peso médio da respectiva unidade, ao final do experimento para análise da composição corporal. As análises bromatológicas das rações e das amostras dos peixes foram realizadas no Laboratório de Nutrição Animal do Departamento de Zootecnia (LNA/DZO) da Universidade Federal de Viçosa - UFV, conforme procedimentos descritos por Silva \& Queiroz(2003).

As deposições de proteína e de gordura corporais foram calculadas pela diferença da proteína ou da gordura corporal final e inicial, respectivamente, em mg, dividida pelo período experimental (dias).

A eficiência de retenção de nitrogênio, expressa em porcentagem, foi calculada pela diferença do nitrogênio corporal final e inicial, dividida pelo nitrogênio total consumido, multiplicada por 100.

As análises estatísticas foram realizadas por meio do programa SAEG - Sistema de Análises Estatísticas e 
Genéticas (UFV, 1997). Os dados foram interpretados por meio de análise de variância a 5\% de probabilidade. Os efeitos dos níveis de lisina digestível foram analisados utilizando-se os modelos de regressão linear, quadrático ou descontínuo Linear Response Plateau (LRP), conforme o melhor ajustamento obtido para cada variável, com base na significância dos coeficientes de regressão pelo teste F, no coeficiente de determinação, na soma de quadrado dos desvios e no fenômeno em estudo.

\section{Resultados e Discussão}

O sistema de abastecimento de água e de aeração possibilitou o controle da temperatura e da aeração uniformes durante o período experimental. Foram obtidos os valores de $28,4 \pm 0,93^{\circ} \mathrm{C}$ para temperatura da água, de $6,6 \pm 0,15$ para o $\mathrm{pH}$ e de 6,24 $\pm 0,46$ ppm para o oxigênio dissolvido. Esses valores encontram-se na faixa recomendada para a criação desta espécie, segundo Furuya (2000) e Kubitza (2000).

Com exceção da taxa de sobrevivência ( $\mathrm{P}>0,05)$, a elevação do nível de lisina digestível da ração influenciou todos os demais parâmetros avaliados nos peixes. Foi observado efeito quadrático $(\mathrm{P}<0,01)$ dos níveis de lisina digestível nas dietas sobre a eficiência de lisina para ganho, que piorou até o nível estimado de 1,696\%, e, para as demais variáveis (ganho de peso, taxa de crescimento específico, consumo de ração, consumo de lisina digestível, conversão alimentar, eficiência proteica para ganho e eficiência de lisina para ganho), observou-se melhora linear $(\mathrm{P}<0,01)$ com a elevação dos níveis de lisina digestível da dieta (Tabela 2; Figura 1).
A taxa média de crescimento de $8,9 \%$ ao dia obtida pelos peixes alimentados com o maior nível de lisina testado foi semelhante àquela de $8,7 \%$ observada por Furuya et al. (2000) e superior àquelas de 7,8 e 7,5\% ao dia verificadas por Lanna et al. (2005) e Bomfim et al. (2005), respectivamente,
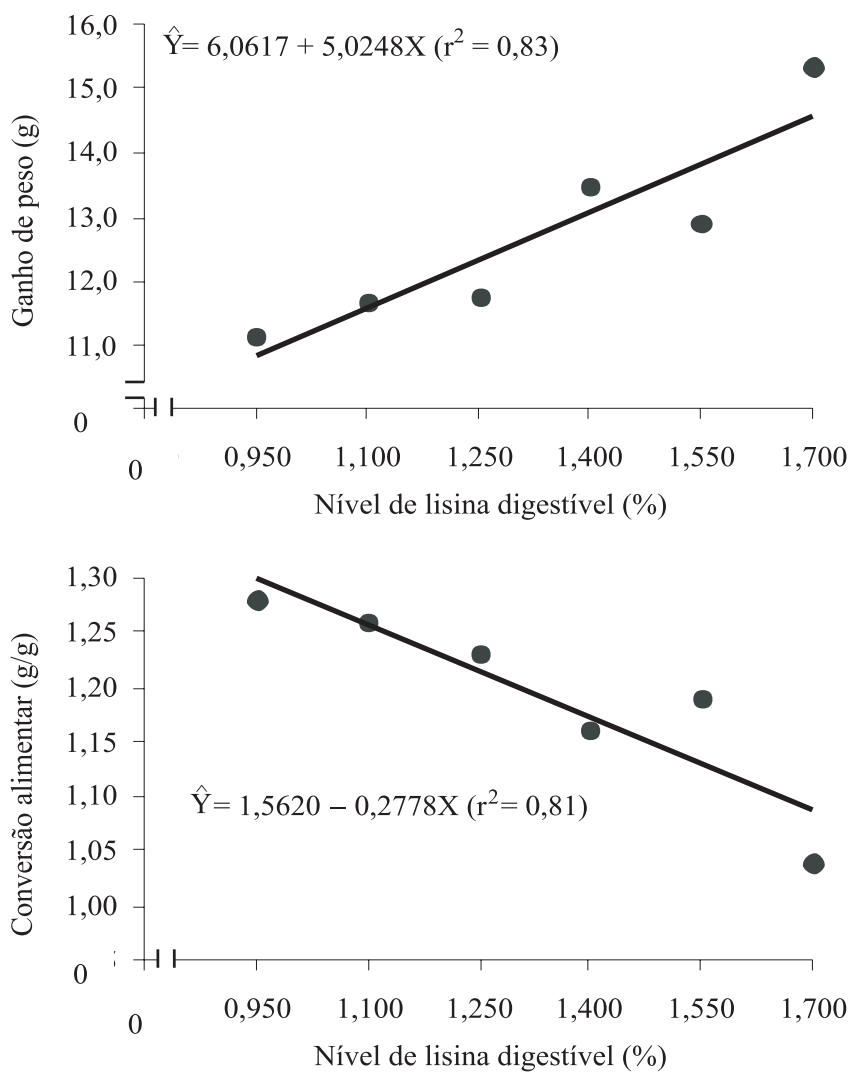

Figura 1 - Ganho de peso e conversão alimentar de alevinos de tilápia-do-nilo, em função do nível de lisina digestível da ração.

Tabela 2 -Desempenho de alevinos de tilápia-do-nilo alimentados com rações com diversos níveis de lisina digestível da ração ${ }^{1}$

\begin{tabular}{|c|c|c|c|c|c|c|c|}
\hline \multirow[t]{2}{*}{ Parâmetro } & \multicolumn{6}{|c|}{ Nível de lisina digestível (\%) } & \multirow[t]{2}{*}{ CV (\%) } \\
\hline & 0,95 & 1,10 & 1,25 & 1,40 & 1,55 & 1,70 & \\
\hline Peso inicial (g) & 1,12 & 1,13 & 1,12 & 1,12 & 1,12 & 1,13 & 1,52 \\
\hline Ganho de peso (g) ${ }^{1}$ & 11,15 & 11,68 & 11,75 & 13,49 & 12,90 & 15,34 & 6,56 \\
\hline Taxa de crescimento específico (\%/dia) ${ }^{2}$ & 7,99 & 8,10 & 8,14 & 8,57 & 8,41 & 8,92 & 2,51 \\
\hline Taxa de sobrevivência (\%) & 100,00 & 100,00 & 100,00 & 100,00 & 100,00 & 100,00 & 0,00 \\
\hline Consumo de ração $(\mathrm{g})^{3}$ & 14,25 & 14,68 & 14,41 & 15,64 & 15,38 & 15,98 & 5,25 \\
\hline Consumo de lisina digestível (mg) ${ }^{4}$ & 135,36 & 161,46 & 180,08 & 218,92 & 238,20 & 271,60 & 5,66 \\
\hline Eficiência de lisina para ganho $(\mathrm{g} / \mathrm{g})^{7}$ & 82,38 & 72,22 & 65,28 & 61,70 & 54,13 & 56,57 & 4,60 \\
\hline
\end{tabular}

CV - coeficiente de variação.

${ }^{1}$ Efeito linear $(\mathrm{P}<0,01)$ : $\hat{\mathrm{Y}}=6,0617+5,0248 \mathrm{X}\left(\mathrm{r}^{2}=0,83\right)$;

${ }^{2}$ Efeito linear $(\mathrm{P}<0,01): \hat{\mathrm{Y}}=6,8236+1,1547 \mathrm{X}\left(\mathrm{r}^{2}=0,85\right)$;

${ }^{3}$ Efeito linear $(\mathrm{P}<0,01): \hat{\mathrm{Y}}=12,0386+2,2746 \mathrm{X}\left(\mathrm{r}^{2}=0,82\right)$;

${ }^{4}$ Efeito linear $(\mathrm{P}<0,01): \hat{\mathrm{Y}}=-38,8971+181,007 \mathrm{X}\left(\mathrm{r}^{2}=0,99\right)$;

${ }^{5}$ Efeito linear $(\mathrm{P}<0,01): \hat{\mathrm{Y}}=1,5620-0,2778 \mathrm{X}\left(\mathrm{r}^{2}=0,81\right)$;

${ }^{6}$ Efeito linear $(\mathrm{P}<0,01): \hat{\mathrm{Y}}=1,9613+0,7045 \mathrm{X}\left(\mathrm{r}^{2}=0,78\right)$;

${ }^{7}$ Efeito quadrático $(\mathrm{P}<0,01): \hat{\mathrm{Y}}=193,692-162,829 \mathrm{X}+48,01 \mathrm{X}^{2}\left(\mathrm{R}^{2}=0,98\right)$. 
nas mesmas condições experimentais e categoria de peso, e nos estudos similares a este conduzidos por Jackson \& Capper(1982), Santiago \& Lovell (1988) e Furuya et al. (2006), com animais de mesma categoria de peso, e por Furuya et al. (2004), com animais na fase de crescimento (118 a 209 g), com valores variáveis entre 1,1 a 6,2\% ao dia (dados calculados).

As taxas de crescimento dos peixes indicam que as rações suplementadas com aminoácidos livres, mesmo com níveis de proteína bruta inferiores às exigências de 32\% para a espécie, segundo Furuya et al. (2000), foram suficientes para potencializar o desempenho dos animais, como também observado por Furuya et al. (2005) e por Bomfim et al. (2005).

Além disso, o melhor balanceamento aminoacídico ocasionado pela redução dos aminoácidos na ração com nível superior de lisina digestível - que, provavelmente, não contribuiriam para a formação de tecido magro e seriam catabolizados - pode ter refletido para maior consumo e conversão alimentar, bem como para maior eficiência proteica para ganho em relação aos obtidos por Furuya et al. (2000), Jackson \& Capper (1982), Furuya et al. (2004), Bomfim et al. (2005), Lanna et al. (2005), Furuya et al. (2005) e Furuya et al. (2006).

Com base nesses resultados, o nível mínimo de lisina digestível nas rações para esta espécie pode ser de 1,70\%. Este valor é superior aos determinados por Jackson \& Capper (1982), de 1,62\%, por Santiago \& Lovell (1988), de 1,43\%, por Furuya et al. (2004), de 1,42\%, cujos valores foram expressos em lisina total, e por Furuya et al. (2006), de 1,44\% de lisina digestível.

Essas diferenças podem ser atribuídas às linhagens de tilápia utilizadas (Jackson \& Capper, 1982; Santiago \& Lovell, 1988) ou à fase de crescimento (Furuya et al., 2004), provável reflexo das menores taxas de crescimento nesses ensaios, que podem resultar em valores de exigência inferiores e compatíveis com sua capacidade de deposição de tecido magro, semelhante ao observado em suínos e aves (Rostagno et al., 2005).

Tem-se observado que linhagens de peixes com maior capacidade de crescimento são mais exigentes em proteína e/ou aminoácidos que as de menor capacidade de crescimento. Em experimentos com essa espécie de peixe para determinação do teor de proteína bruta nas rações para as linhagens tailandeza e comum, foram determinados valores de exigência de 32\% (Furuya et al., 2000) e 29,9\% (Furuya et al., 1996), respectivamente. A linhagem tailandesa apresenta maior capacidade de ganho de peso diário em comparação à comum (Boscolo et al., 2002a). Desta forma, a utilização dos valores determinados por Jackson \& Capper (1982) e Santiago \& Lovell (1988), os quais utilizaram linhagens de tilápia comuns, podem subestimar as exigências dietéticas de lisina para as linhagens atuais, justificando, em parte, as diferenças observadas neste estudo. Além disso, peixes na fase inicial (alevinos) apresentam exigência dietética de proteína (aminoácidos) superior à de peixes na fase de crescimento e terminação (NRC, 1993; Furuya et al., 2004; Wilson, 2003), o que pode justificar os maiores valores obtidos em relação ao estudo conduzido por Furuya et al. (2004).

Outra hipótese seria baseada na deficiência de alguns aminoácidos indispensáveis nas rações com níveis mais elevados de lisina, cuja relação aminoácido:lisina teria ficado inferior à mínima calculada com base nos valores de exigência estabelecido pelo NRC (1993), limitando a resposta dos animais alimentados por deficiência de algum outro aminoácido essencial (Conhalato et al, 2000; Fontes et al., 2000; Valério et al., 2003; Bomfim et al., 2005; Abreu et al., 2006). Essa pode ser a causa das diferenças em relação ao estudo conduzido por Furuya et al. (2006), em que os níveis fixados para treonina, triptofano, isoleucina e arginina resultaram em relações aminoácido:lisina inferiores às mínimas estimadas com base nos valores de exigência estabelecidos pelo NRC (1993) para o maior nível de lisina digestível testado (1,74\%).

A elevação do s teores de lisina digestível resultou em aumento linear dos valores de proteína corporal (Figura 2), deposições diárias de proteína e gordura corporais e eficiência de retenção de nitrogênio $(P<0,05)$ e redução do teor de umidade corporal $(\mathrm{P}<0,05)$, sem, contudo influenciar $(\mathrm{P}>0,05)$ no teor de gordura corporal dos peixes (Tabela 3 ).

O aumento no teor de proteína e na deposição proteica corporal, além de confirmar os valores de exigência mínimo

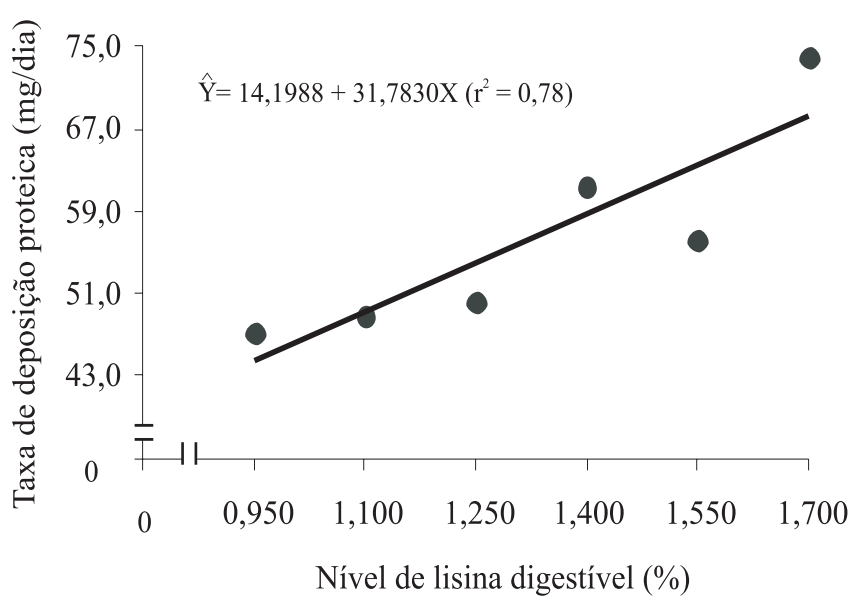

Figura 2 - Deposição proteica corporal de alevinos de tilápia-donilo alimentados com rações nível de lisina digestível. 
Tabela 3 - Composição corporal, deposições diárias de proteína e gordura corporais e eficiência de retenção de nitrogênio de alevinos de tilápia-do-nilo alimentados com rações com diversos níveis de lisina digestível

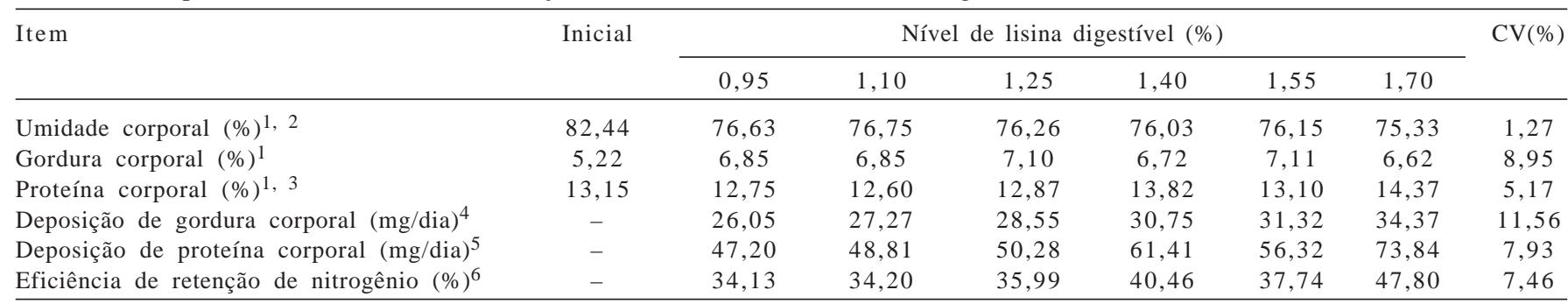

CV-coeficiente de variação.

1 Matéria natural.

${ }^{2}$ Efeito linear $(\mathrm{P}<0,05): \hat{\mathrm{Y}}=78,3489-1,62736 \mathrm{X}\left(\mathrm{r}^{2}=0,81\right)$;

${ }^{3}$ Efeito linear $(\mathrm{P}<0,01): \hat{\mathrm{Y}}=10,5963+1,9779 \mathrm{X}\left(\mathrm{r}^{2}=0,69\right)$;

${ }^{4}$ Efeito linear $(\mathrm{P}<0,01): \hat{\mathrm{Y}}=15,5846+10,6659 \mathrm{X}\left(\mathrm{r}^{2}=0,97\right)$;

${ }^{5}$ Efeito linear $(\mathrm{P}<0,01): \hat{\mathrm{Y}}=14,1988+31,7830 \mathrm{X}\left(\mathrm{r}^{2}=0,78\right)$;

${ }^{6}$ Efeito linear $(\mathrm{P}<0,01): \hat{\mathrm{Y}}=17,3339+15,8896 \mathrm{X}\left(\mathrm{r}^{2}=0,74\right)$.

determinado com base nos resultados obtidos por meio dos parâmetros de desempenho e eficiência alimentar, indica que o teor energético utilizado não foi limitante nos processos de deposição de proteína corporal (crescimento) (Boscolo et al., 2006).

A ausência de diferenças no teor de gordura corporal e a elevação linear da deposição de gordura corporal não eram esperadas na análise da associação desta variável aos resultados de deposição proteica corporal e conversão alimentar. Considerando que a máxima eficiência alimentar é alcançada no ponto em que o animal atinge seu potencial para deposição de proteína, menor quantidade de energia deveria estar disponível para deposição de gordura corporal (Fontes et al., 2000; Bureau et al., 2000; Noblet, 2001; Abreu et al., 2006).

Contudo, o aumento do consumo de ração e de energia e o melhor balanceamento aminoacídico, reduzindo a quantidade de aminoácidos excedentes para serem catabolizados e, consequentemente, o aumento calórico, resultando em uma maior fração de energia líquida para ser depositada na forma de gordura corporal, podem ter compensado o maior gasto energético para a deposição de proteína corporal dos peixes alimentados com as rações de elevado teor de lisina digestível (Bureau et al., 2000; Noblet, 2001; Dabrowski \& Guderley, 2002).

Apesar da piora na eficiência de utilização de lisina para ganho de peso nos peixes com a elevação dos níveis de lisina digestível, essa piora foi compensada por uma substancial melhora no desempenho como um todo e principalmente na deposição proteica corporal e eficiência de utilização da fração nitrogenada da ração.

Uma vez que as rações com níveis elevados de lisina demandaram mais aminoácidos sintéticos, essa piora na eficiência de utilização de lisina para ganho de peixes pode ser atribuída, segundo alguns autores: à limitada eficiência na utilização de aminoácidos sintéticos; à possibilidade de ter ocorrido lixiviação dos aminoácidos no ambiente aquático; ou ao desbalanceamento do perfil aminoacídico ideal dietético (Schuhmacher et al., 1997; Zorate\&Lovell,1997; Zorateetal., 1999; Dabrowski etal., 2003; Lanna et al., 2005).

Os aminoácidos sintéticos apresentam maiores velocidades de evacuação estomacal e absorção em relação àqueles oriundos da proteína "intacta”, o que pode resultar em elevação excessiva e precoce nas concentrações plasmáticas desses aminoácidos nos sítios de síntese proteica, aumentando seu catabolismo, o que pode resultar em desequilíbrio no pool de aminoácidos necessários para a síntese proteica, com consequências à utilização dos demais aminoácidos (Tantikitti \& March, 1995; Schuhmacher et al., 1997; Zorate \& Lovell, 1997; Zorate et al., 1999; Aoki et al., 2001).

Por outro lado, esses problemas podem ser reduzidos pela utilização de níveis moderados de aminoácidos (El-Husseiny et al., 2002) e intervalos mais curtos de alimentação (mínimo de quatro vezes/dia), o que pode estabilizar concentração plasmática dos aminoácidos e compatibilizar a capacidade/velocidade de síntese proteica pelos tecidos especializados, potencializando a utilização da fração nitrogenada (Tantikitti \& March, 1995; Zorate et al., 1999; Barroso et al., 1999; Rodehutscord et al, 2000; Lanna, 2005).

Nesta pesquisa, como o alimento foi peletizado e fornecido seis vezes ao dia, em quantidades pequenas e em repasses sucessivos para garantir a rápida e completa ingestão das rações, e não foram observadas sobras durante a alimentação, é pouco provável que tenha ocorrido lixiviação de aminoácidos sintéticos e/ou desbalanços nos sítios de síntese proteica em quantidades significativas que pudessem comprometer essa variável. 
A hipótese mais provável para a redução nos valores da eficiência de utilização de lisina para ganho é alguma relação aminoácido:lisina, estabelecida pelo NRC (1993), ter sido subestimada, apesar da margem de segurança adotada neste estudo.

Considerando os valores obtidos em estudos recentes de exigências dietéticas mínima de treonina (Silva et al., 2006) e de lisina (Furuya et al., 2006) totais de 1,35\% e de 1,56\%, respectivamente, cujo valor mínimo estimado da relação treonina:lisina seria de $87 \%$, os níveis de treonina utilizado nas rações de maior teor de lisina (77\%) podem ter sido limitantes.

\section{Conclusões}

O nível de 1,80\% de lisina total (0,600\% Mcal de ED) e o de $1,70 \%$ de lisina digestível (0,567\% Mcal de ED) proporcionam melhores resultados de desempenho e características de carcaça de alevinos de tilápia-do-nilo quando se utiliza o conceito de proteína ideal na formulação das rações experimentais.

\section{Referências}

ABREU, M.L.T.; DONZELE, J.L.; OLIVEIRA, R.F.M. et al. Níveis de lisina digestível em rações, utilizando-se o conceito de proteína ideal, para suínos machos castrados de alto potencial genético dos 15 aos $30 \mathrm{~kg}$. Revista Brasileira de Zootecnia, v.35, n.3, p.1039-1046, 2006 (supl.).

AOKI, H.; AKIMOTO, A.; WATANABE, T. Periodical changes of plasma free amino acid levels and feed digesta in yellowtail after feeding non-fish meal diets with or without supplemental crystalline amino acids. Fisheries Science, v.67, p.614-618, 2001.

BARROSO, J.B.; PERAGÓN, J.; GARCÍA-SALGUERO, L. et al. Variations in the kinetic behavior of the NADPH-production systems in different tissues of the trout when fed on an amino-acid-based diet at different frequencies. The International Journal of biochemistry \& Cell Biology, v.31, p.277-290, 1999.

BOISEN, S.; HVELPLUND, T.; WEISBJERG, M.R. Ideal amino acid profiles as a basis for feed protein evaluation. Livestock Production Science, v.64, p.239-251, 2000.

BOISEN, S. ideal dietary amino acid profiles for pigs. In: Amino acid in farm animal nutrition. Wallingford: CAB International, 2003. p.157-168.

BOMFIM, M.A.D.; LANNA, E.A.T.; DONZELE, J.L. et al. Redução de proteína bruta com suplementação de aminoácidos, com base no conceito de proteína ideal, em dietas para tilápia do Nilo (Oreochromis niloticus) - resultados preliminares In: REUNIÃO ANUAL DA SOCIEDADE BRASILEIRA DE ZOOTECNIA, 42., 2005, Goiânia. Anais... Goiânia, 2005a. (CD-ROM).

BOSCOLO, W.R.; HAYASHI, C.; MEURER, F. Desempenho e características de carcaça de machos revertidos de tilápias do Nilo (Oreochromis niloticus, L.), linhagens tailandesa e comum, nas fases inicial e crescimento Revista Brasileira de Zootecnia, v.31, n.2, p.539-545, 2002a.

BOSCOLO, W.R.; HAYASHI, C.; MEURER, F. Digestibilidade aparente da energia e nutrientes de alimentos convencionais e alternativos para a tilápia do Nilo (Oreochromis niloticus, L.) Revista Brasileira de Zootecnia, v.31, n.2, p.539-545, 2002b.
BOSCOLO, W.R.; FEIDEN, A.; SIGNOR, A. et al. Energia digestível para alevinos de tilápia-do-Nilo (Oreochromis niloticus, L.) Revista Brasileira de Zootecnia, v.35, n.3, p.629-633, 2006. BUREAU, B.P.; AZEVEDO, P.A.; TAPIA-SALAZAR, M. et al. Pattern and cost of growth and nutrient deposition in fish and shrimp: Potential implications and applications. In: SIMPOSIUM INTERNACIONAL DE NUTRICIÓN ACUÍCOLA, Avances en Nutrición Acuícola, 5., 2000, Mérida, Yucatán, Mexico. Memorias... Mérida: 2000. (CD-ROM).

CONHALATO, G.S.; DONZELE, J.L; OLIVEIRA, R.F.M. et al. Avaliação de rações contendo diferentes níveis de lisina digestível mantendo a relação aminoacídica para pintos de corte na fase de 1 a 21 dias se idade. Revista Brasileira de Zootecnia, v.31, n.2, p.539-545, 2002.

COWEY, C.B. Amino acid requirements of fish: a critical appraisal of present values. Aquaculture, v.124, p.1-11, 1994.

DABROWSKI, K.; GUDERLEY, H. Intermediary metabolism. In: HALVER, J.E.; HARDY, R.W. (Ed.) Fish nutrition. 3.ed. Washington: Academic Press, 2002. p.309-365.

DABROWSKI, K.; LEE, K.; RINCHARD, J. The smallest vertebrate, teleost fish, can utilize synthetic dipeptide-based diets. Journal Nutrition, v.133, p.4225-4229, 2003.

EL-HUSSEINY, O.M.; GODA, A.M.A.S.; SULOMA, A.M. Utilization of amino acids in Nile tilapia (Oreochromis niloticus) fry. 1 - Utilization efficiency of synthetic amino acid by Nile tilapia fry. Veterinary Medical Journal Giza, v.50, n.1, p.47-59, 2002.

FONTES, D.O.; DONZELE, J.C.; OLIVEIRA, R.F.M. et al. Níveis de lisina para leitoas selecionadas geneticamente para deposição de carne magra, dos 30 aos $60 \mathrm{~kg}$, mantendo constante a relação entre metionina + cistina, treonina, triptofano, isoleucina e valina. Revista Brasileira de Zootecnia, v.29, n.3, p.776-783, 2000.

FURUYA, W.M.; HAYASHI, C.; FURUYA, V.R.B et al. Exigência de proteína para machos revertidos de tilápia do Nilo (Oreochromis niloticus) na fase juvenil. Revista Unimar, v.18, n.2, p.307-319, 1996.

FURUYA, W.M.; HAYASHI, C.; FURUYA, V.R.B. et al. Exigência de proteína para alevino revertido de tilápia do Nilo (Oreochromis niloticus). Revista Brasileira de Zootecnia, v.26, n.6, p.1912-1917, 2000 (supl. 1).

FURUYA, W.N. Digestibilidade aparente de aminoácidos e substituição da proteína da farinha de peixe pela proteína do farelo de soja com base no conceito da proteína ideal em rações para tilápia do Nilo (Oreochromis niloticus). 2000. 69f. Dissertação (Doutorado em Zootecnia) - Faculdade de Medicina Veterinária e Zootecnia/Universidade Estadual Paulista, Botucatu.

FURUYA, W.M.; BOTARO, D.; NEVES, P.R. et al. Exigência de lisina pela tilápia do Nilo (Oreochromis niloticus), na terminação. Ciência Rural, v.34, n.5, p.1571-1577, 2004.

FURUYA, W.M.; BOTARO, D.; MACEDO, R.M.G. et al. Aplicação do conceito de proteína ideal para redução dos níveis de proteína em dietas para tilápia-do-nilo (Oreochromis niloticus). Revista Brasileira de Zootecnia, v.34, n.5, p.1433-1441, 2005.

FURUYA, W.M.; BOTARO, D.; SANTOS, V.G. et al. Exigências de lisina digestível para juvenis de tilápia-do-Nilo. Revista Brasileira de Zootecnia, v.35, n.3, p.937-942, 2006 (supl.).

HAULER, R.C.; CARTER, C.G. Reevaluation of the quantitative dietary lysine requirements of fish. Reviews in Fisheries Science, v.9, n.3, p.133-166, 2001.

JACKSON, A.J.; CAPPER, B.S. Investigations into the requirements of the tilapia Sarotherodon mossambicus for dietary methionine, lysine and arginine in semi-synthetic diets. Aquaculture, v.29, p.289-297, 1982.

KUBITZA, F. Tilápia: tecnologia e planejamento na produção comercial. Jundiaí: F. Kubitza, 2000. 285p.

LANNA, E.A.T.; QUADROS, M.; BOMFIM, M.A.D. et al. Freqüência de alimentação em alevinos de tilápia do Nilo (Oreochromis niloticus) utilizando dietas de baixo teor proteico suplementadas com aminoácidos - resultados preliminares. In: REUNIÃO 
ANUAL DA SOCIEDADE BRASILEIRA DE ZOOTECNIA, 42., 2005, Goiânia. Anais... Goiânia, 2005. (CD-ROM).

NATIONAL RESEARCH COUNCIL - NRC. Nutrient requirements of fish. Washington: National Academy of Science, 1993. 105p.

NOBLET, J. Avaliação energética em suínos. In: WORKSHOP LATINO-AMERICANO AJINOMOTO BIOLATINA DE NUTRIÇÃO DE AVES E SUÍNOS, 2001, Foz do Iguaçu. Anais... Foz do Iguaçu: 2001. p.2-17.

PEZZATO, L.E.; MIRANDA, E.C.; BARROS, M.M. et al. Digestibilidade aparente de ingredientes pela tilápia do Nilo (Oreochromis niloticus). Revista Brasileira de Zootecnia, v.31, n.4, p.1595-1604, 2002.

ROLLIN, X.; MAMBRINI, M.; ABBOUDI, T. et al. The optimum dietary indispensable amino acid pattern for growing Atlantic salmon (Salmo salar L.) fry. British Journal of Nutrition, v.90, p.865-876, 2003.

ROSTAGNO, R.S.; ALBINO, L.F.T.; DONZELE, J.L. et al. Tabelas brasileiras para aves e suínos - composição de alimentos e exigências nutricionais. 2.ed. Viçosa, MG: Universidade Federal de Viçosa, 2005. 186p.

RODEHUTSCORD, M.; BORCHERT, F.; GREGUS, K. et al. Availability and utilization of free lysine in rainbow trout Oncorhynchus mykiss. 1. Effect of dietary crude protein level. Aquaculture, v.187, p.163-176, 2000.

SANTIAGO, C.B.; LOVELL, R.T. Amino acid requirements for growth of Nile tilapia. Journal of Nutrition, v.118, p.1540-1546, 1988.

SILVA, L.C.R.; FURUYA, W.M.; SANTOS, L.D. et al. Níveis de treonina em rações para tilápias-do-Nilo. Revista Brasileira de Zootecnia, v.35, n.4, p.1258-1264, 2006.
SILVA, D.J; QUEIROZ, A.C. Análise de alimentos (métodos químicos e biológicos). 3.ed. Viçosa, MG: Universidade Federal de Viçosa, 2002. 235p.

SCHUHMACHER, A.; WAX, C.; GROPP, J.M. Plasma amino acids in rainbow trout (Oncorhynchus mykiss) fed intact protein or a crystalline amino acid diet. Aquaculture, v.151, p.15-28, 1997.

TANTIKITTI, C.; MARCH, B.E. Dynamics of plasma free amino acids in rainbow trout (Oncorhynchus mykiss) under variety of dietary conditions. Fish Physiology and Biochemistry, v.14, p.179-194, 1995.

UNIVERSIDADE FEDERAL DE VIÇOSA - UFV. Sistemas de Análises Estatísticas e Genéticas - SAEG. Viçosa, MG: 1997 (Versão 8.0). 142p.

VALÉRIO, S.R.; OLIVEIRA, R.F.M; DONZELE, J.L. et al. Níveis de lisina digestível em rações, em que se manteve ou não a relação aminoacídica, para frangos de corte de 22 a 42 dias de idade, mantidos em estresse por calor. Revista Brasileira de Zootecnia, v.32, n.2, p.372-382, 2003.

WILSON, R.P. Amino acid requirements of finfish and crustaceans. In: D’MELLO, J.P.F. (Ed.) Amino acid in farm animal nutrition. Wallingford: CAB International, 2003. p.427-447.

ZARATE, D.D.; LOVELL, R.T. Free lysine (L-lysine - $\mathrm{HCl}$ ) is utilized for growth less efficiently than protein-bound lysine (soybean meal) in practical diets by young channel catfish (Ictalurus punctatus). Aquaculture, v.159, p.87-100, 1997.

ZARATE, D.D.; LOVELL, R.T; PAYNE, M. Effects of feeding frequency and rate of stomach evacuation on utilization of dietary free and protein-bound lysine for growth by channel catfish Ictalurus punctatus. Aquaculture Nutrition, v.5, p.17-22, 1999. 